\title{
Novel Polymer-Silica Composite-Based Bifunctional Catalysts for Hydrodeoxygenation of 4-(2-Furyl)-3-Buten-2-One as Model Substance for Furfural-Acetone Aldol Condensation Products
}

\author{
Michael Goepel ${ }^{1, * \mathbb{D}}$, Ruben Ramos ${ }^{2}$, Roger Gläser ${ }^{1}$ and David Kubička $^{3}$ (D) \\ 1 Institute of Chemical Technology, Universität Leipzig Linnéstr. 3, 04103 Leipzig, Germany; \\ roger.glaeser@uni-leipzig.de \\ 2 Faculty of Sciences, University of Porto, 4169-007 Porto, Portugal; rrvelarde@hotmail.com \\ 3 Department of Petroleum Technology and Alternative Fuels, University of Chemistry and Technology \\ Prague, Technická 5, Dejvice, 16628 Prague 6, Czech Republic; david.Kubicka@vscht.cz \\ * Correspondence: michael.goepel@uni-leipzig.de
}

Received: 30 April 2019; Accepted: 12 June 2019; Published: 14 June 2019

check for updates

Featured Application: Through the coprecipitation of acidic polymers with silica and subsequent metal doping of the obtained acid composite, novel and bifunctional metal polymer-silica composite catalysts with tunable acidic and redox properties were to be obtained. In the hydrodeoxygenation of 4-(2-furyl)-3-buten-2-one, a relevant platform chemical in biomass upgrading, the product composition could be engineered by adjusting the polymer and metal loading.

\begin{abstract}
Novel bifunctional metal-loaded polymer-silica composite (PSC) catalysts were investigated in the hydrodeoxygenation (HDO) of 4-(2-furyl)-3-buten-2-one (FAc) as a model substance for furfural-acetone aldol condensation products. PSC catalysts were synthesized via a sol-gel method with different polymer contents and subsequently doped with different noble metals. The product composition of the HDO of FAc could be tuned by using catalysts with different polymer (i.e., acidic properties) and metal content (i.e., redox properties), showing the great potential of metal-loaded PSC materials as tunable catalysts in biomass conversions with complex reaction networks. Furthermore, high yields ( $>90 \%$ ) of the fully hydrodeoxygenated product (n-octane) could be obtained using noble metal-loaded PSC catalysts in only $8 \mathrm{~h}$ of reaction time.
\end{abstract}

Keywords: bifunctional; acid; redox; composite; catalyst; silica; polymer; biomass upgrading; hydrodeoxygenation; furfural-acetone condensation

\section{Introduction}

The conversion of bio-based instead of fossil resources to value-added chemicals is considered a promising and sustainable approach to overcome current global challenges such as, fossil fuel shortage, environmental problems, and climate change [1,2]. In the broad field of processes converting bio-derived products, liquid phase processing of biomass is a less energy-intensive alternative to gasification or pyrolysis followed by Fischer-Tropsch synthesis [3]. In the liquid phase conversion of lignocellulose, the most abundant, cheapest, and fastest growing biomass resource on earth, furfural is obtained as an important platform chemical [4,5]. Due to its relative short carbon chain length, further processing of furfural to yield organic molecules with higher carbon content is of general interest for the synthesis of fuel additives and value-added chemicals [6,7]. One recent research strategy 
to obtain longer carbon chain organic molecules is based on the acid- [8-10] or base-catalyzed [11] aldol condensation of furfural with acetone and subsequent dehydration to 4-(2-furyl)-3-butene-2-one (FAc). The acetone for this reaction can also be obtained from bio-based resources via fermentation [12] or ketonization [13].

A further hydrodeoxygenation (HDO) of FAc is of key interest for the production of fuel additives and value-added chemicals and has been investigated in recent studies $[10,14,15]$. The reaction network for the HDO of FAc (requiring both acid and redox catalyst functionalities) is very complex, and the reaction may yield a broad variety of different products apart from the fully deoxygenated $n$-octane. For example, 1-octanol was identified as a valuable intermediate for the HDO of FAc [16]. While 1-octanol can be produced from FAc in biphasic aqueous reaction mixtures making use of its immiscibility with water [17], another approach to simply engineer the product composition of the FAc, HDO using a tailored catalyst is desirable. For this, a bifunctional catalyst whose acid and redox properties can be individually tuned would be of great interest.

In this context, polymer-silica composite (PSC) catalysts offer great potential as an acid component of tailorable bifunctional catalysts. They have been first synthesized by Harmer et al. [18] at DuPont by embedding Nafion ${ }^{\circledR}$ type polymers into silica matrices by coprecipitation. In this work, Harmer et al. furthermore showed that the acid site density of these PSC-catalysts could simply be tuned by polymer content. In addition to that, they attributed an improved performance of the PSC catalysts over conventional Nafion ${ }^{\circledR}$-based ion-exchange resin solid acid catalysts (i.e., Amberlyst-15 and NR50, which possess higher acid capacities) to the higher dispersion of the polymer species in the PSC catalysts. Despite their obvious potential as solid acid catalyst, and their application as (reference) catalyst in numerous studies [19-23], there are only a few studies published further investigating the PSC catalysts themselves. Harmer et al. found that the silica precursor used for the PSC catalyst synthesis might affect the catalytic performance [24]. Furthermore, the influence of polymer content on textural properties and catalytic performance in different acylation reactions was investigated by Schuster et al. [25,26].

Concerning PSC-based bifunctional catalysts, only two studies could be found in the literature. In these investigations, $\mathrm{Pt}$ and $\mathrm{Pd}$ were added to the commercial SAC-13 catalyst via impregnation and the catalysts were used in the direct hydroxylation of benzene $[27,28]$. When comparing these PSC-based bifunctional catalysts to conventional ion-exchange resins (Amberlyst-15) [28] and with other Pt- and Pd-modified acid catalysts (such as BEA, FER, MOR, and MFI zeolites), the PSC-based bifunctional catalyst showed a fivefold higher formation rate of phenol than all the other catalysts investigated in both studies. However, in these works, the amount of polymer (given by the loading of the commercial catalyst) and metal content was not varied and no content-dependent investigations were carried out.

It is therefore the aim of this study to investigate the potential of metal-loaded PSC as tailorable catalysts in the HDO of FAc. For this purpose, PSC-based catalysts with varying polymer contents (0-26 wt.\%) were synthesized and loaded with different amounts (0.5-2 wt.\%) of noble metals $(\mathrm{Pt}, \mathrm{Pd}, \mathrm{Ru})$. These bifunctional catalysts with unique adjustable redox and acidic properties were used in the HDO of FAc, as a complex reaction network with multiple desirable products, to investigate the influence of redox and acid properties on the product composition. This approach may further contribute to the rational understanding of the design of heterogeneous catalysts for the production of drop-in fuels from lignocellulose-derived furan compounds.

\section{Materials and Methods}

\subsection{Chemicals Used}

4-(2-Furyl)-3-buten-2-one (FAc, cis + trans, 98\%) and Nafion D-520 dispersion solution (5 wt.\% in water and 1-propanol) were purchased from Alfa Aesar (Haverhill, MA, USA). Cyclohexane (>99.99\%) was purchased from Lach-Ner Chemicals (Neratovice, Czech Republic). (5)Pt-Escat (5 wt.\% 
Pt on alumina powder) was purchased from ABCR (Karlsruhe, Germany). Tetramethylorthosilicate (TMOS, $\geq 98 \%$ ), ruthenium(III) nitrosyl nitrate solution $\left(\mathrm{Ru}(\mathrm{NO})\left(\mathrm{NO}_{3}\right)_{\mathrm{x}}(\mathrm{OH})_{\mathrm{y}}, \mathrm{x}+\mathrm{y}=3,1.5 \mathrm{wt} . \% \mathrm{Ru}\right)$, palladium(II) nitrate dihydrate $\left(\mathrm{Pd}\left(\mathrm{NO}_{3}\right)_{2} \cdot 2 \mathrm{H}_{2} \mathrm{O}, 40 \mathrm{wt} . \% \mathrm{Pd}\right)$, and tetraammineplatinum(II) nitrate $\left(\mathrm{Pt}\left(\mathrm{NH}_{3}\right)_{4}\left(\mathrm{NO}_{3}\right)_{2}, 99.995 \%\right.$ trace metal basis) were purchased from Sigma Aldrich (St. Louis, MO, USA). Hydrogen gas (Air Liquide, Paris, France) was used with a purity of $99.9 \%$.

\subsection{Catalyst Preparation}

The polymer-silica composite (PSC) catalysts were prepared adapting a literature procedure [24]. For a typical catalyst synthesis (13 wt.\% of polymer) a mixture of $19.81 \mathrm{~cm}^{3} \mathrm{Si}(\mathrm{OMe})_{4}$ and $0.30 \mathrm{~cm}^{3}$ $\mathrm{HCl}(0.04 \mathrm{M})$ in $3.30 \mathrm{~cm}^{3} \mathrm{H}_{2} \mathrm{O}$ was stirred for $60 \mathrm{~min}$ at $25^{\circ} \mathrm{C}$ to ensure the hydrolysis of the silica precursor. In parallel, a solution of $15.00 \mathrm{~cm}^{3} \mathrm{NaOH}(0.4 \mathrm{M})$ was added dropwise to $30.00 \mathrm{~cm}^{3}$ of a Nafion D-520 dispersion solution ( $5 \mathrm{wt} . \%$ of Nafion in water and 1-propanol, corresponding to $1.5 \mathrm{~g}$ of polymer) and stirred for $15 \mathrm{~min}$ at $25^{\circ} \mathrm{C}$. The silica-containing solution was then added rapidly to the basic Nafion-containing solution and gelation to a slightly transparent solid occurred in less than $30 \mathrm{~s}$. The gel was then thermally treated at $95{ }^{\circ} \mathrm{C}$ under air atmosphere for $24 \mathrm{~h}$. Afterward, the solid product was crushed to obtain grain sizes $<0.2 \mathrm{~mm}$ and washed five times with $20 \mathrm{~cm}^{3}$ of $\mathrm{HNO}_{3}$ (25 wt.\%) and subsequently five times with $20 \mathrm{~cm}^{3}$ of distilled water. For different polymer contents, the amount of Nafion dispersion solution in the synthesis mixture was adjusted accordingly. The samples were named according to the polymer content in wt.\% (i.e., (13)PSC: polymer-silica composite catalyst with $13 \mathrm{wt} . \%$ polymer content).

The addition of the metal was carried out via incipient wetness impregnation process. For this, an appropriate amount of the PSC catalyst was treated with a $0.1 \mathrm{M}$ aqueous solution of $\mathrm{Pt}\left(\mathrm{NH}_{3}\right)_{4}\left(\mathrm{NO}_{3}\right)_{2}$, $\mathrm{Pd}\left(\mathrm{NO}_{3}\right)_{2} \cdot 2 \mathrm{H}_{2} \mathrm{O}$, or a solution of $\mathrm{Ru}(\mathrm{NO})\left(\mathrm{NO}_{3}\right)_{x}(\mathrm{OH})_{y}(\mathrm{x}+\mathrm{y}=3)$ in dilute nitric acid containing $1.5 \mathrm{wt} . \%$ of $\mathrm{Ru}$ for the impregnation with platinum, palladium, and ruthenium, respectively. The solutions were added dropwise to the solids under stirring for $10 \mathrm{~min}$. Afterward the samples were treated at $95^{\circ} \mathrm{C}$ under air atmosphere for $12 \mathrm{~h}$.

\subsection{Catalyst Characterization}

Nitrogen sorption isotherms were recorded at $-196{ }^{\circ} \mathrm{C}$ using an Autosorb instrument (Quantachrome). Elemental analysis was carried out dissolving the sample quantitatively in $15 \mathrm{~cm}^{3}$ of aqua regia, evaporating the solution and again adding $15 \mathrm{~cm}^{3}$ of aqua regia to the remaining solid. This solution was then heated to the boiling point, and the solids were then removed by filtration and rinsed with deionized water. The filtrate was collected and diluted with deionized water to obtain $50 \mathrm{ml}$ of solution. This solution was analyzed using an inductively coupled plasma optical emission spectrometer (Agilent 725). The thermogravimetric investigations were carried out in a temperature range between 50 and $800^{\circ} \mathrm{C}$ (ramp: $10^{\circ} \mathrm{C} \mathrm{min}-1$ ) using a Discovery series (TA instruments).

\subsection{Catalytic Investiagtions}

The catalytic experiments were carried out in a $300 \mathrm{ml}$ high-pressure batch reactor (Parr Instruments Co.) equipped with digital controls for pressure, temperature, and stirring speed. The reaction parameters were monitored and recorded via a 4848B acquisition interface (Parr Instruments Co., (Frankfurt, Germany). Additionally, the reactor was equipped with a preheating unit.

Prior to the catalytic reaction, the reactor was flushed with hydrogen three times and the catalyst $(0.25 \mathrm{~g})$ was reduced in situ overnight under a static atmosphere of 20 bar hydrogen at $250{ }^{\circ} \mathrm{C}$ for $5 \mathrm{~h}$ (ramp: $8{ }^{\circ} \mathrm{C} \mathrm{min}{ }^{-1}$ ). After cooling down to room temperature, the reactor was depressurized to 5 bar and preheated to the desired reaction temperature (usually $250^{\circ} \mathrm{C}$ ). Simultaneously, the preheating unit was loaded with the reaction solution (containing $0.5 \mathrm{~g}$ FAc $\left(24.5 \mathrm{mmol} \mathrm{l}^{-1}\right)$ dissolved in $150 \mathrm{ml}$ of cyclohexane and $1 \mathrm{ml}$ of $n$-hexadecane as internal standard), flushed three times with hydrogen and also preheated to the desired reaction temperature. The catalytic reaction was then started by charging the preheated reaction solution into the reactor, adjusting the hydrogen pressure to the desired value 
(usually 100 bar), and setting the desired stirring speed (usually $1000 \mathrm{~min}^{-1}$ ). Subsequently, the first liquid sample was taken (0 min). Additional samples were collected after 10, 30, 60, 90, 120, 180, 240, 360 , and $480 \mathrm{~min}$ of reaction time.

These samples were analyzed by gas chromatography (GC) using an Agilent 7890A GC equipped with a flame ionization detector and a HP-5 capillary column $(30 \mathrm{~m}, 0.32 \mathrm{~mm}$ i.d., $0.25 \mu \mathrm{m}$ film). The GC-mass-spectrometry (MS) based peak identification was based on an earlier work [29] and conducted using a Thermo Scientific ITQ 1100 unit (Thermo Fischer, Waltham, MA, USA). The catalytic results could be reproduced within a standard deviation of $<10 \%$. The calculation of product concentrations was also based on earlier work [29]. Since different furan isomers could not be distinguished by GC-MS and due to the general complexity of the reaction network, in this study all products in which the ring is not yet opened are considered half-hydrogenated $(\mathrm{HH})$ as displayed in Figure 1. In addition to that, the alcohols were also summarized as one product group to simplify the presentation of the results. This grouping of products closely follows the reaction pathway for the HDO of FAc suggested by Xia et al. [30]. The product fractions have been calculated by using the following formula:

$$
z=\frac{\sum_{i=1}^{n} c_{i}}{\sum_{i=1}^{m} c_{i}}
$$

where, $z$ is the product fraction, $\sum_{i=1}^{n} c_{i}$ is the sum of the respective concentrations of products associated to the product group, and $\sum_{i=1}^{m} c_{i}$ is the summed-up concentration of all products observed.

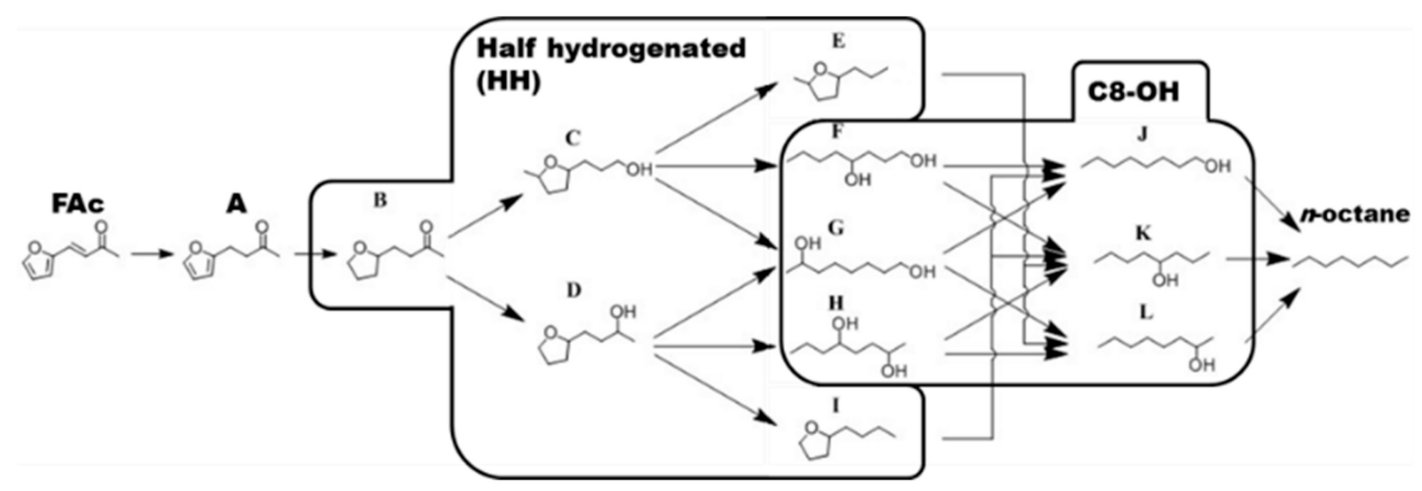

Figure 1. Reaction scheme for the hydrodeoxygenation of 4-(2-furyl)-3-buten-2-one (FAc), reaction scheme adapted from [30].

In case not all isomers could be clearly identified via GC-MS and/or no reference substances were available for calibration, the same response factor was assumed for groups of isomers. Using this method the carbon balance could be closed $\geq 95 \%$ for reactions with $n$-octane product fractions ( $\left.z_{n \text {-octane }}\right)$ $>0.8$ and $\geq 80 \%$ for $n$-octane product fractions ( $\left.\mathrm{z}_{n \text {-octane }}\right) \leq 0.8$.

\section{Results}

\subsection{Catalyst Properties}

The characterization via nitrogen sorption at $-196^{\circ} \mathrm{C}$ shows similar isotherm shapes for all catalysts investigated. The isotherm of (1) $\mathrm{Pt}(13) \mathrm{PSC}$ is exemplarily given in Figure S1 in the Supplementary Materials. The textural characterization data is summarized in Table 1. As can be seen for the catalysts (1) $\mathrm{Pt} /(0) \mathrm{PSC}$, (1)Pt/(6.5)PSC, (1)Pt/(13)PSC, and (1)Pt/(26)PSC and their respective specific surface areas $\left(182,168,131\right.$, and $\left.105 \mathrm{~cm}^{3} \mathrm{~g}^{-1}\right)$, an increase in polymer content reduces the specific surface area of the silica-polymer composite obtained from the sol-gel synthesis. This observation is in agreement with earlier findings [25] and is caused by the addition of nonporous polymer to the porous silica 
matrix. The polymer content has been determined by TGA experiments, calculating the polymer content via weight loss in a temperature range between 350 and $500{ }^{\circ} \mathrm{C}$. This method was already used by Liu et al. [31] and validated by them via additional measurements with sulfur elemental analysis and pyridine adsorption experiments and found to be accurate for polymer-silica composites. The obtained results indicate a complete inclusion of the polymer added to sol-gel mixture in the silica-polymer composite. The metal content, as determined by inductively coupled plasma optical emission spectrometry (ICP-OES), shows a high efficiency of the incipient wetness impregnation method used. The determined content was within $90 \%$ of the aimed content for all catalysts synthesized except for (0.5)Pt(13)PSC, where only $86 \%$ of the aimed content was observed (Table 1).

Table 1. Specific surface area $A_{B E T}$, specific pore volume $V_{\text {pore, }}$ and average pore width $\mathrm{d}_{\text {pore }}$ determined from $\mathrm{N}_{2}$ sorption at $-196{ }^{\circ} \mathrm{C}$ as well as polymer content determined by thermogravimetric analysis (TGA) and metal content determined via inductively coupled plasma optical emission spectrometry (ICP-OES) for different noble metal-loaded polymer-silica composite (PSC) catalysts.

\begin{tabular}{|c|c|c|c|c|c|}
\hline Catalyst & $A_{B E T} /\left(m^{2} g^{-1}\right)$ & $\mathrm{V}_{\text {pore }} /\left(\mathrm{cm}^{3} \mathrm{~g}^{-1}\right)$ & $\mathrm{d}_{\text {pore }} / \mathrm{nm}$ & $\begin{array}{c}\text { Polymer } \\
\text { Content/wt. } \%\end{array}$ & $\begin{array}{c}\text { Metal } \\
\text { Content/wt. } \%\end{array}$ \\
\hline (1)Pt(0)PSC & 182 & 0.40 & 9.1 & 0.0 & 0.91 \\
\hline (1) $\mathrm{Pt}(6.5) \mathrm{PSC}$ & 168 & 0.38 & 9.0 & 6.3 & 0.95 \\
\hline (13)PSC & 134 & 0.30 & 9.2 & 13.1 & n.d. \\
\hline (0.5) $\mathrm{Pt}(13) \mathrm{PSC}$ & 125 & 0.29 & 9.0 & 12.7 & 0.43 \\
\hline (1)Pt(13)PSC & 131 & 0.35 & 8.9 & 12.6 & 0.92 \\
\hline (2)Pt(13)PSC & 130 & 0.33 & 9.1 & 12.8 & 1.83 \\
\hline (1)Pt(26)PSC & 105 & 0.24 & 9.5 & 25.1 & 0.95 \\
\hline (1)Pd(13)PSC & 133 & 0.33 & 8.9 & 12.8 & 0.92 \\
\hline (1)Ru(13)PSC & 115 & 0.34 & 9.0 & 12.5 & 0.96 \\
\hline
\end{tabular}

\subsection{Catalytic Investigations}

The HDO of FAc has a complex reaction network which has recently been investigated by Ramos et al. [29] and whose detailed reaction pathways have not yet been fully understood. The reaction scheme used in this study (Figure 1) has been adapted from a recent investigation of the $\mathrm{HDO}$ of FAc in aqueous phase by $\mathrm{Xu}$ et al. [32].

Furthermore, some of the reaction products observed are grouped to enable easier data processing of the multicomponent reaction mixture and to better highlight the hydrogenation (redox) and acidic properties of the metal/polymer-silica composite catalysts. In the context of this categorization, the concentration over reaction time profile for the grouped reactants in the HDO of FAc using (1) $\mathrm{Pt}(13) \mathrm{PSC}$ is given in Figure 2. The results support the reaction mechanism proposed in Figure 1 and can be considered representative for the HDO of FAc using bifunctional metal/polymer-silica composite catalysts as conducted in this study. The allylic double bond of FAc is hydrogenated first to form 4-(2-Furyl)-2-butanone (A) which is consistent with literature reports [29]. Then, (A) is further hydrogenated to the products that are considered "half-hydrogenated (HH)" in this study. The acid-catalyzed ring-opening reaction then happens in a consecutive reaction step. However, the hydrogenation can also occur before the ring opening. Waidmann et al. [33] furthermore pointed out that the acid-catalyzed ring opening of biomass-derived furan rings depends on the substitution pattern of the furan ring. Since this pattern can change during the reaction due to acid-catalyzed isomerization reactions $[29,34]$, the position of the ring opening is affected by multiple factors. 


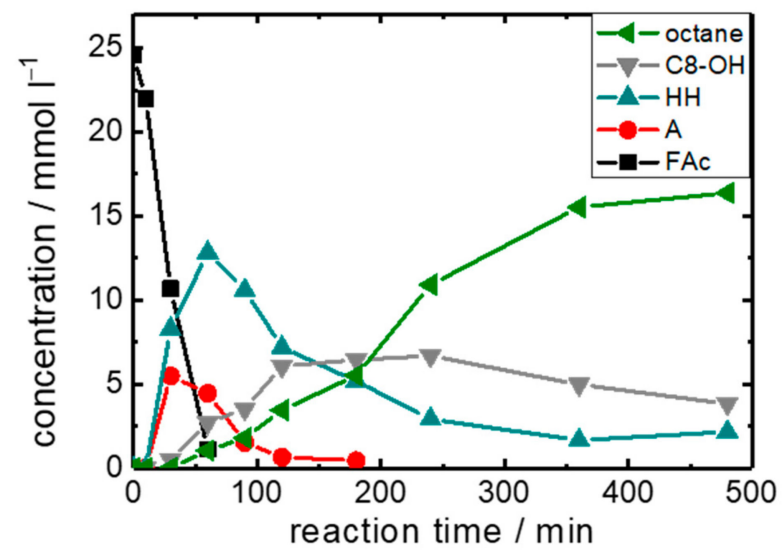

Figure 2. Reactant concentration over time for the hydrodeoxygenation (HDO) of 4-(2-furyl)3-buten-2-one (FAc) carried out using (1)Pt(13)PSC $\left(\mathrm{T}=250{ }^{\circ} \mathrm{C}, \mathrm{p}_{\mathrm{H} 2}=100 \mathrm{bar}, \mathrm{m}_{\text {catalyst }}=0.25 \mathrm{~g}\right.$, $0.5 \mathrm{~g} \mathrm{FAc}\left(24.5 \mathrm{mmol} \mathrm{l}^{-1}\right)$ dissolved in $150 \mathrm{ml}$ cyclohexane, stirring speed $\left.=1000 \mathrm{~min}^{-1}\right)$.

Since in the literature the HDO of FAc has been carried out at a wide variety of different $\mathrm{H}_{2}$ pressures (from 10 [30] to 120 bar [16]), first an investigation of the influence of the hydrogen pressure on the product composition in the HDO of FAc was conducted (Figure 3). Upon increasing the hydrogen pressure from 30 to $60 \mathrm{bar}$, an increase in $n$-octane in the product fraction from 0.20 to 0.68 was observed. This is in agreement with the findings by Xia et al. [30], where also an increase in $n$-octane yield with increasing hydrogen pressure for the $\mathrm{HDO}$ of FAc using $\mathrm{Pd} / \mathrm{NbOPO}_{4}$ as a catalyst and cyclohexane as a solvent in a fixed-bed reactor was observed in a pressure range from 10 to 20 bar. Above a hydrogen pressure of 60 bar, no influence on the product composition was observed. Thus, to fully exclude an influence of hydrogen pressure on the results obtained, all other reactions were carried out at a hydrogen pressure of 100 bar.

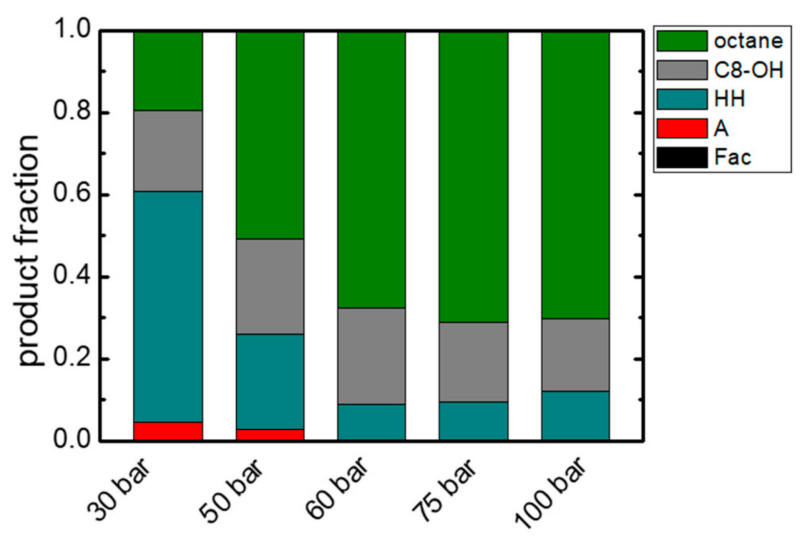

Figure 3. Product fractions obtained for the HDO of FAc carried out using (1)Pt(13)PSC at different hydrogen pressures $\left(\mathrm{T}=250{ }^{\circ} \mathrm{C}, \mathrm{m}_{\text {catalyst }}=0.25 \mathrm{~g}, 0.5 \mathrm{~g}\right.$ FAc $\left(24.5 \mathrm{mmol} \mathrm{L}{ }^{-1}\right)$ dissolved in $150 \mathrm{~mL}$ cyclohexane, stirring speed $=1000 \mathrm{~min}^{-1}, \mathrm{X}(\mathrm{FAc})>99 \%$ ).

FAc is usually produced via aldol condensation of furfural [35] with acetone as a solvent and reactant. Thus, carrying out the consecutive HDO of FAc also using acetone as a solvent is desirable. However, in presence of an acidic catalyst, acetone undergoes self-condensation reactions (Figure S2) severely slowing down the HDO reaction. Since acetone can additionally undergo condensation reaction with many of the intermediate products of the HDO of FAc, an even more complex reaction network and reduced octane yields are obtained. This has already been reported elsewhere [29]. Isopropanol was investigated as an alternative solvent, but also reacts at the employed reaction conditions. The reaction products (presumably propylene [36]) were not further investigated and 
quantified due to their gaseous nature. The HDO of FAc was thus conducted using cyclohexane as a solvent, which was chemically inert in the presence of (1)Pt(13)PSC at $250{ }^{\circ} \mathrm{C}$ and a hydrogen pressure of 100 bar for at least $8 \mathrm{~h}$ of reaction time.

\subsubsection{Influence of Polymer Content/Acidic Properties}

The product composition of the HDO of FAc as a function of the polymer content of the bifunctional metal/polymer-silica composite catalysts is given in Figure 4. As expected, no conversion of the substrate was observed in absence of a catalyst. For the catalyst containing Pt but no acidic polymers $((1) \mathrm{Pt}(0) \mathrm{PSC})$, no ring-opened products were observed, indicating that the silica gel alone does not possess acidic sites strong enough to catalyze the ring-opening reaction. However, when increasing the polymer content (from 6.5 to $26 \mathrm{wt} . \%$ ) and with that the acid site density of polymer-based acid sites of the catalysts, the product fraction of ring-opened products ( $n$-octane and $\mathrm{C}_{8}-\mathrm{OH}$ ) increased from 0.32 over 0.90 to 1.00 for the catalysts (1)Pt(6.5)PSC, (1)Pt(13)PSC and (1)Pt(26)PSC, respectively. This is in agreement with what has been published about the importance of support acidity in the HDO of bio-oils using Pt catalysts [37]. Furthermore, it nicely demonstrates the potential to engineer product yield in complex reaction networks via polymer doping of the catalyst.

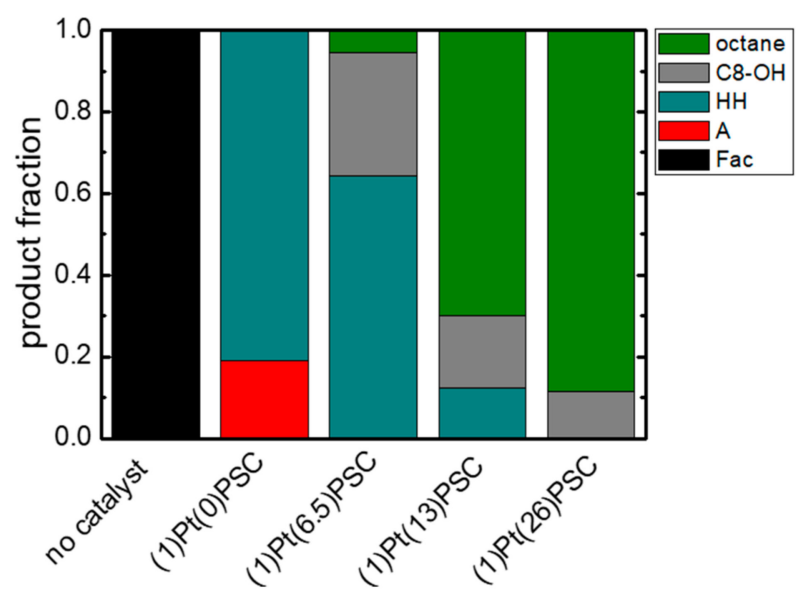

Figure 4. Product fractions obtained for the HDO of FAc carried out using polymer-silica composite (PSC) catalysts doped with $1 \mathrm{wt} . \% \mathrm{Pt}$ and different polymer contents $\left(\mathrm{T}=250{ }^{\circ} \mathrm{C}, \mathrm{p}_{\mathrm{H} 2}=100 \mathrm{bar}, \mathrm{m}_{\text {catalyst }}\right.$ $=0.25 \mathrm{~g}, 0.5 \mathrm{~g}$ FAc $\left(24.5 \mathrm{mmol} \mathrm{l}^{-1}\right)$ dissolved in $150 \mathrm{ml}$ cyclohexane, stirring speed $=1000 \mathrm{~min}^{-1}, \mathrm{X}(\mathrm{FAc})$ $>99 \%$ except for no catalyst).

\subsubsection{Influence of Platinum Content/Redox Properties}

Furthermore, the platinum content of the catalysts was varied with a constant polymer content of $13 \mathrm{wt} . \%$ (Figure 5). No conversion was observed for the PSC catalyst without metal content ((13)PSC) which was expected due to the lack of hydrogenation active metal sites, and further confirms the proposed reaction scheme for the HDO of FAc given in Figure 1, in which ring opening can only occur after hydrogenation. When adding metal to (13)PSC, hydrogenated and ring-opened products are observed. A strong increase of catalyst activity in terms of yield of half-hydrogenated $(\mathrm{HH})$ and ring-opened $\left(\mathrm{C}_{8}-\mathrm{OH}\right.$ and $n$-octane) products was observed when the Pt content was increased from 0.5 to $1 \mathrm{wt} . \%$ ((0.5)Pt(13)PSC) and (1)Pt(13)PSC, respectively). No significant change in product yield was obtained when the Pt content was further increased to $2 \mathrm{wt} . \%$. This is in agreement with the acid-catalyzed ring-opening step being rate limiting for the HDO of FAc to $n$-octane under the conditions applied. This has also been suggested in the literature [17] and is also consistent with the findings in Section 3.2.1, where increasing $n$-octane yields were observed with increasing polymer content (Figure 3). 


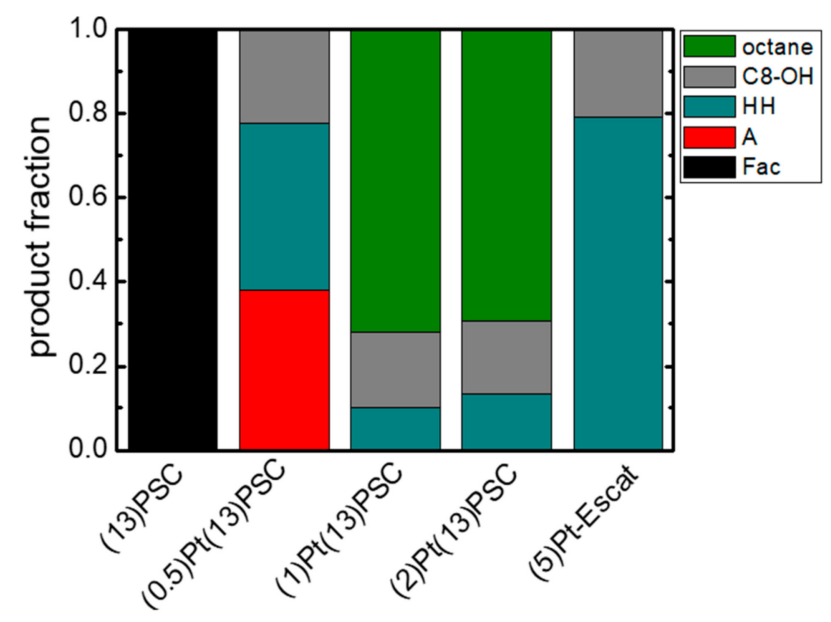

Figure 5. Product fractions obtained for the HDO of FAc carried out using PSC catalysts containing 13 wt. $\%$ polymer and different Pt contents $\left(\mathrm{T}=250{ }^{\circ} \mathrm{C}, \mathrm{p}_{\mathrm{H} 2}=100 \mathrm{bar}, \mathrm{m}_{\text {catalyst }}=0.25 \mathrm{~g}, 0.5 \mathrm{~g}\right.$ FAc $\left(24.5 \mathrm{mmol} \mathrm{L}^{-1}\right)$ dissolved in $150 \mathrm{~mL}$ cyclohexane, stirring speed $=1000 \mathrm{~min}^{-1}, \mathrm{X}(\mathrm{FAc})>99 \%$ except for (13)PSC).

When further comparing the novel metal/polymer-silica composite catalyst (1)Pt(13)PSC with a commercially available Pt catalyst (Pt supported on $\gamma$-alumina, (5)Pt-Escat) it can be seen that higher product fractions of ring-opened products $(0.90 \mathrm{vs}$. 0.21$)$ were yielded with a lower noble metal content (1 wt.\% vs. $5 \mathrm{wt}$ \%) for (1)Pt(13)PSC as compared to (5)Pt-Escat. It is noteworthy that using (5)Pt-Escat as catalyst, a small product fraction of ring-opened products ( 0.21$)$ can be observed. This is probably due to its higher support acidity as compared to (1) $\mathrm{Pt}(0) \mathrm{PSC}$. The absence of $n$-octane in the product fraction in the reaction using (5)Pt-Escat furthermore illustrates that acidic sites of different strength may be necessary for the ring opening on the one hand, and the final dehydration reaction of the alcohol to the alkane on the other hand. This is in agreement with results published by Luska et al. [16] where Ru-nanoparticle-SILP (supported ionic liquid phase) catalysts were used for the HDO of 4-(2-tetrahydrofuryl)-2-butanol, an intermediate in the HDO of FAc. And although ring-opened products were obtained in yields $>90 \%$ no, or only very low yields $(<3 \%)$ of $n$-octane were observed.

\subsubsection{Influence of the Noble Metal}

To further investigate the potential of the metal-loaded PSC as tunable catalysts, a variation of the active metal phase used was carried out. For this reason the (13)PSC polymer-silica composite was impregnated with palladium ((1)Pd(13)PSC) and ruthenium ((1) $\mathrm{Ru}(13) \mathrm{PSC})$. As it can be seen in Figure 6, the product composition for (1)Pd(13)PSC did not significantly differ from (1)Pt(13)PSC, again indicating a possible limitation of the reaction to $n$-octane by the acid-catalyzed ring-opening reaction. This is in agreement with the findings from Xia et al. [17] who also found comparable product compositions in the $\mathrm{HDO}$ of FAc for Pt and Pd supported on $\mathrm{NbOPO}_{4}$ using water as a solvent. Also comparable to their paper, the results using ruthenium as active metal ((1)Ru(13)PSC) differ from the former two. This supports their argument that in the HDO of FAc the active metal may not only act as a hydrogenation catalyst, but also affect the product selectivity due to synergistic effects (e.g., with the support material). The exceptional performance of Ru as a HDO catalyst has also been discussed elsewhere in the recent literature $[38,39]$ and although the mechanistic details are not fully understood it can be summarized that the product composition in the HDO of FAc can also be tuned via the metal component of the metal/polymer-silica composite catalysts investigated. 


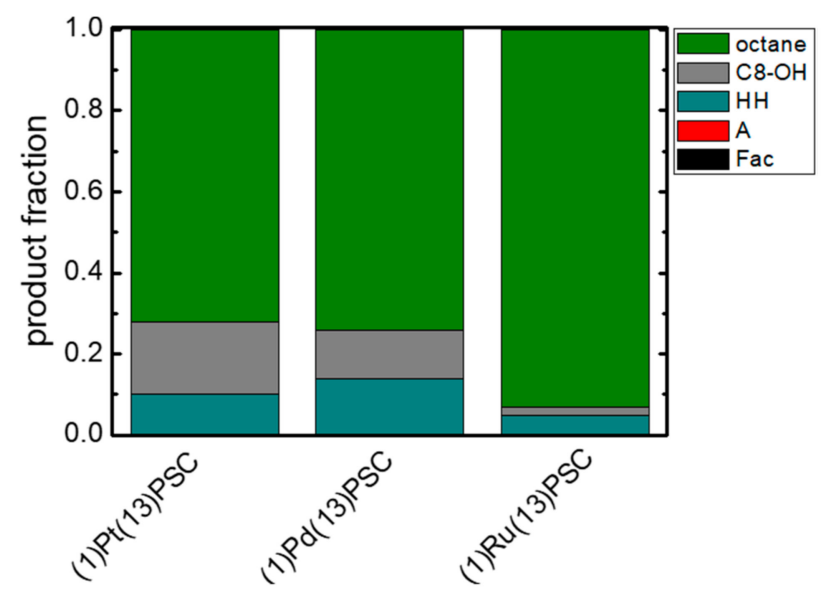

Figure 6. Product fractions obtained for the HDO of FAc carried out using PSC catalysts containing $13 \mathrm{wt} . \%$ polymer and $1 \mathrm{wt} . \%$ metal content with different active noble metals $\left(\mathrm{T}=250{ }^{\circ} \mathrm{C}, \mathrm{p}_{\mathrm{H} 2}=100 \mathrm{bar}\right.$, $\mathrm{m}_{\text {catalyst }}=0.25 \mathrm{~g}, 0.5 \mathrm{~g}$ FAc $\left(24.5 \mathrm{mmol} \mathrm{l}^{-1}\right)$ dissolved in $150 \mathrm{ml}$ cyclohexane, stirring speed $=1000 \mathrm{~min}^{-1}$, $\mathrm{X}(\mathrm{FAc})>99 \%)$.

It is furthermore noteworthy comparing the conversion of FAc to $n$-octane obtained in this study with the few studies conducted in the literature under similar conditions. The $n$-octane product fraction of 0.9 (roughly equaling $90 \%$ yield of $n$-octane) observed after $8 \mathrm{~h}$ of reaction time at $250{ }^{\circ} \mathrm{C}$ and $100 \mathrm{bar}$ $\mathrm{H}_{2}$ using (1) Ru(13)PSC with a catalyst to reactant mass ratio of $1: 2$ is comparable to the $94 \%$ yield obtained by Xia et al. [30] at $170{ }^{\circ} \mathrm{C}, 20 \mathrm{bar}_{2}$, the same catalyst to reactant mass ratio (but a higher noble metal content of $5 \mathrm{wt} . \%$ ) after $24 \mathrm{~h}$ of reaction time using a $\mathrm{Pd} / \mathrm{Nb}_{2} \mathrm{O}_{5} / \mathrm{SiO}_{2}$ catalyst. For a more detailed report on the productivity of different bifunctional catalysts in the HDO of FAc, see Table S1.

\section{Discussion}

Novel bifunctional metal-loaded polymer-silica composite (PSC) catalysts with different polymer and metal contents have been successfully synthesized. These materials were used in the HDO of FAc as a relevant reaction in the context of creating fuels and value-added chemicals from lignocellulose-derived biomass, which proceed via a complex reaction network of acid and redox-catalyzed steps. A maximum yield of $n$-octane (the final product in the HDO of FAc) of $90 \%$ was obtained at $250^{\circ} \mathrm{C}, 100$ bar of $\mathrm{H}_{2}$, and after $8 \mathrm{~h}$ of reaction time. The catalytic performance of the synthesized materials was significantly affected by both the metal and the polymer content, illustrating the tailorable catalytic properties of the metal-loaded PSC catalysts. Although more studies are required to shed light on the direct correlation between the catalytic properties and the reaction pathways, the obtained results illustrate the potential of metal-loaded PSC catalysts as tunable bifunctional catalyst for the complete deoxygenation of biomass-derived compounds.

Supplementary Materials: The following are available online at http://www.mdpi.com/2076-3417/9/12/2438/s1, Figure S1: Volume adsorbed $\left(\mathrm{V}_{\text {ads }}\right)$ over relative pressure $\left(\mathrm{p} / \mathrm{p}_{0}\right)$ from $\mathrm{N}_{2}$ sorption for $(1) \mathrm{Pt}(13) \mathrm{PSC}$ recorded at $-196{ }^{\circ} \mathrm{C}$. Figure S2: Reactant concentration of the self-condensation products of acetone over time for the HDO of FAc carried out using (1)Pt(13)PSC as a catalyst and acetone as a solvent $\left(\mathrm{T}=250{ }^{\circ} \mathrm{C}, \mathrm{p}_{\mathrm{H} 2}=100 \mathrm{bar}\right.$, $\mathrm{m}_{\text {catalyst }}=0.25 \mathrm{~g}, 0.5 \mathrm{~g}$ FAc $\left(24.5 \mathrm{mmol} \mathrm{l}^{-1}\right)$ dissolved in $150 \mathrm{ml}$ acetone, stirring speed $\left.=1000 \mathrm{~min}^{-1}\right)$. Figure S3: Product fractions obtained for the reusability studies of (1) $\mathrm{Pt}(13) \mathrm{PSC}$ in the HDO of FAc $\left(\mathrm{T}=250{ }^{\circ} \mathrm{C}, \mathrm{p}_{\mathrm{H} 2}=100 \mathrm{bar}\right.$, $\mathrm{m}_{\text {catalyst }}: \mathrm{m}_{\mathrm{FAc}}=2: 1, \mathrm{c}_{\mathrm{FAc}}=24.5 \mathrm{mmol} \mathrm{l}^{-1}$, solvent: cyclohexane, stirring speed $\left.=1000 \mathrm{~min}^{-1}\right)$. The catalyst was washed five times with $50 \mathrm{ml}$ cyclohexane and subsequently dried for $5 \mathrm{~h}$ at $200{ }^{\circ} \mathrm{C}$ in an air atmosphere between the experiments. Table S1: Productivity (given as mmol octane produced per gram of noble metal and hour) and reaction conditions for the hydrodeoxygenation of 4-(2-furyl)-3-buten-2-one reported in literature and this work ((1)Ru(13)PSC)).

Author Contributions: Data curation, R.R.; funding acquisition, D.K.; investigation, M.G. and R.R.; supervision, R.G. and D.K.; writing — original draft, M.G.; writing—review and editing, R.G. and D.K. 
Funding: This research was funded by Czech Science Foundation, grant number P106/12/G015 and carried out at the UniCRE center (CZ.1.05/2.1.00/03.0071) whose infrastructure was supported by the European Regional Development Fund and the state budget of the Czech Republic.

Acknowledgments: Acknowledgments go to FPS COST Action FP1306 (Valorization of Lignocellulosic Biomass Side Streams for Sustainable Production of Chemicals, Materials \& Fuels using Low Environmental Impact Technologies).

Conflicts of Interest: The authors declare no conflict of interest.

\section{References}

1. Chheda, J.N.; Dumesic, J.A. An overview of dehydration, aldol-condensation and hydrogenation processes for production of liquid alkanes from biomass-derived carbohydrates. Catal. Today 2007, 123, 59-70. [CrossRef]

2. Stocker, M. Biofuels and biomass-to-liquid fuels in the biorefinery: Catalytic conversion of lignocellulosic biomass using porous materials. Angew. Chem. Int. Ed. 2008, 47, 9200-9211. [CrossRef] [PubMed]

3. Chheda, J.N.; Huber, G.W.; Dumesic, J.A. Liquid-phase catalytic processing of biomass-derived oxygenated hydrocarbons to fuels and chemicals. Angew. Chem. Int. Ed. 2007, 46, 7164-7183. [CrossRef] [PubMed]

4. Xing, R.; Subrahmanyam, A.V.; Olcay, H.; Qi, W.; van Walsum, G.P.; Pendse, H.; Huber, G.W. Production of jet and diesel fuel range alkanes from waste hemicellulose-derived aqueous solutions. Green Chem. 2010, 12, 1933. [CrossRef]

5. Lange, J.-P.; van der Heide, E.; van Buijtenen, J.; Price, R. Furfural—A promising platform for lignocellulosic biofuels. ChemSusChem 2012, 5, 150-166. [CrossRef]

6. Faba, L.; Diaz, E.; Ordonez, S. One-pot aldol condensation and hydrodeoxygenation of biomass-derived carbonyl compounds for biodiesel synthesis. ChemSusChem 2014, 7, 2816-2820. [CrossRef]

7. Kikhtyanin, O.; Kubička, D.; Čejka, J. Toward understanding of the role of Lewis acidity in aldol condensation of acetone and furfural using MOF and zeolite catalysts. Catal. Today 2015, 243, 158-162. [CrossRef]

8. Kubička, D.; Kikhtyanin, O. Opportunities for zeolites in biomass upgrading-Lessons from the refining and petrochemical industry. Catal. Today 2015, 243, 10-22. [CrossRef]

9. Barrett, C.J.; Chheda, J.N.; Huber, G.W.; Dumesic, J.A. Single-reactor process for sequential aldol-condensation and hydrogenation of biomass-derived compounds in water. Appl. Catal. B Environ. 2006, 66, 111-118. [CrossRef]

10. Faba, L.; Díaz, E.; Ordóñez, S. Hydrodeoxygenation of acetone-furfural condensation adducts over alumina-supported noble metal catalysts. Appl. Catal. B Environ. 2014, 160, 436-444. [CrossRef]

11. Kikhtyanin, O.; Bulanek, R.; Frolich, K.; Cejka, J.; Kubicka, D. Aldol condensation of furfural with acetone over ion-exchanged and impregnated potassium BEA zeolites. J. Mol. Catal. A Chem. 2016, 424, 358-368. [CrossRef]

12. Van der Wal, H.; Sperber, B.L.H.M.; Houweling-Tan, B.; Bakker, R.R.C.; Brandenburg, W.; Lopez-Contreras, A.M. Production of acetone, butanol, and ethanol from biomass of the green seaweed Ulva lactuca. Bioresour. Technol. 2013, 128, 431-437. [CrossRef] [PubMed]

13. Pham, T.N.; Shi, D.; Sooknoi, T.; Resasco, D.E. Aqueous-phase ketonization of acetic acid over Ru/TiO2/carbon catalysts. J. Catal. 2012, 295, 169-178. [CrossRef]

14. Chatterjee, M.; Matsushima, K.; Ikushima, Y.; Sato, M.; Yokoyama, T.; Kawanami, H.; Suzuki, T. Production of linear alkane via hydrogenative ring opening of a furfural-derived compound in supercritical carbon dioxide. Green Chem. 2010, 12, 779. [CrossRef]

15. Ramos, R.; Tisler, Z.; Kikhtyanin, O.; Kubicka, D. Solvent effects in hydrodeoxygenation of furfural-acetone aldol condensation products over $\mathrm{Pt} / \mathrm{TiO}_{2}$ catalyst. Appl. Catal. A Gen. 2017, 530, 174-183. [CrossRef]

16. Luska, K.L.; Julis, J.; Stavitski, E.; Zakharov, D.N.; Adams, A.; Leitner, W. Bifunctional nanoparticle-SILP catalysts (NPs@SILP) for the selective deoxygenation of biomass substrates. Chem. Sci. 2014, 5, 4895-4905. [CrossRef]

17. Xia, Q.; Xia, Y.; Xi, J.; Liu, X.; Wang, Y. Energy-efficient production of 1-octanol from biomass-derived furfural-acetone in water. Green Chem. 2015, 17, 4411-4417. [CrossRef]

18. Harmer, M.A.; Farneth, W.E.; Sun, Q. High Surface Area Nafion + Resin/Silica Nanocomposites: A New Class of Solid Acid Catalyst. J. Am. Chem. Soc. 1996, 118, 7708-7715. [CrossRef] 
19. Gallo, J.M.R.; Alamillo, R.; Dumesic, J.A. Acid-functionalized mesoporous carbons for the continuous production of 5-hydroxymethylfurfural. J. Mol. Catal. A Chem. 2016, 422, 13-17. [CrossRef]

20. Ozbay, N.; Oktar, N.; Dogu, G.; Dogu, T. Activity Comparison of Different Solid Acid Catalysts in Etherification of Glycerol with tert-Butyl Alcohol in Flow and Batch Reactors. Top. Catal. 2013, 56, 1790-1803. [CrossRef]

21. Liu, Y.; Lotero, E.; Goodwinjr, J.G. Effect of carbon chain length on esterification of carboxylic acids with methanol using acid catalysis. J. Catal. 2006, 243, 221-228. [CrossRef]

22. Meylemans, H.A.; Quintana, R.L.; Rex, M.L.; Harvey, B.G. Low-temperature, solvent-free dehydration of cineoles with heterogeneous acid catalysts for the production of high-density biofuels. J. Chem. Technol. Biotechnol. 2014, 89, 957-962. [CrossRef]

23. Wang, H.; Xu, B.-Q. Catalytic performance of $\mathrm{Nafion} / \mathrm{SiO}_{2}$ nanocomposites for the synthesis of $\alpha$-tocopherol. Appl. Catal. A Gen. 2004, 275, 247-255. [CrossRef]

24. Harmer, M.A.; Sun, Q.; Vega, A.J.; Farneth, W.E.; Heidekum, A.; Hoelderich, W.F. Nafion resin-silica nanocomposite solid acid catalysts. Microstructure-processing-property correlations. Green Chem. 2000, 2, 7-14. [CrossRef]

25. Schuster, H.; Hoelderich, W.F. The acylation of 2-methoxynaphthalene with acetic anhydride over Nafion/silica composites and BEA zeolites containing Lewis acid sites. Appl. Catal. A Gen. 2008, 350, 1-5. [CrossRef]

26. Harmer, M.A.; Farneth, W.E.; Sun, Q. Towards the Sulfuric Acid of Solids. Adv. Mater. 1998, 10, $1255-1257$. [CrossRef]

27. Laufer, W.; Niederer, J.P.M.; Hoelderich, W.F. New Direct Hydroxylation of Benzene with Oxygen in the Presence of Hydrogen over Bifunctional Palladium/Platinum Catalysts. Adv. Synth. Catal. 2002, 344, 1084-1089. [CrossRef]

28. Laufer, W.; Hoelderich, W.F. New direct hydroxylation of benzene with oxygen in the presence of hydrogen over bifunctional ion-exchange resins. Chem. Commun. 2002, 1684-1685. [CrossRef]

29. Ramos, R.; Tišler, Z.; Kikhtyanin, O.; Kubička, D. Towards understanding the hydrodeoxygenation pathways of furfural-acetone aldol condensation products over supported Pt catalysts. Catal. Sci. Technol. 2016, 6, 1829-1841. [CrossRef]

30. Xia, Q.-N.; Cuan, Q.; Liu, X.-H.; Gong, X.-Q.; Lu, G.-Z.; Wang, Y.-Q. Pd/NbOPO 4 multifunctional catalyst for the direct production of liquid alkanes from aldol adducts of furans. Angew. Chem. Int. Ed. 2014, 53, 9755-9760. [CrossRef]

31. Liu, Y.; Lotero, E.; Goodwinjr, J.G. A comparison of the esterification of acetic acid with methanol using heterogeneous versus homogeneous acid catalysis. J. Catal. 2006, 242, 278-286. [CrossRef]

32. Xu, W.; Xia, Q.; Zhang, Y.; Guo, Y.; Wang, Y.; Lu, G. Effective production of octane from biomass derivatives under mild conditions. ChemSusChem 2011, 4, 1758-1761. [CrossRef] [PubMed]

33. Waidmann, C.R.; Pierpont, A.W.; Batista, E.R.; Gordon, J.C.; Martin, R.L.; “Pete” Silks, L.A.; West, R.M.; $\mathrm{Wu}, \mathrm{R}$. Functional group dependence of the acid catalyzed ring opening of biomass derived furan rings: An experimental and theoretical study. Catal. Sci. Technol. 2013, 3, 106-115. [CrossRef]

34. Shao, Y.; Xia, Q.; Liu, X.; Lu, G.; Wang, Y. $\mathrm{Pd} / \mathrm{Nb}_{2} \mathrm{O}_{5} / \mathrm{SiO}_{2}$ catalyst for the direct hydrodeoxygenation of biomass-related compounds to liquid alkanes under mild conditions. ChemSusChem 2015, 8, 1761-1767. [CrossRef] [PubMed]

35. Kikhtyanin, O.; Kelbichová, V.; Vitvarová, D.; Kubů, M.; Kubička, D. Aldol condensation of furfural and acetone on zeolites. Catal. Today 2014, 227, 154-162. [CrossRef]

36. Bedia, J.; Rosas, J.M.; Vera, D.; Rodríguez-Mirasol, J.; Cordero, T. Isopropanol decomposition on carbon based acid and basic catalysts. Catal. Today 2010, 158, 89-96. [CrossRef]

37. Wang, Y.; Wu, J.; Wang, S. Hydrodeoxygenation of bio-oil over Pt-based supported catalysts: Importance of mesopores and acidity of the support to compounds with different oxygen contents. RSC Adv. 2013, 3, 12635. [CrossRef] 
38. Michel, C.; Gallezot, P. Why Is Ruthenium an Efficient Catalyst for the Aqueous-Phase Hydrogenation of Biosourced Carbonyl Compounds? ACS Catal. 2015, 5, 4130-4132. [CrossRef]

39. Pritchard, J.; Filonenko, G.A.; van Putten, R.; Hensen, E.J.M.; Pidko, E.A. Heterogeneous and homogeneous catalysis for the hydrogenation of carboxylic acid derivatives: History, advances and future directions. Chem. Soc. Rev. 2015, 44, 3808-3833. [CrossRef] 